\title{
High expression of carcinoembryonic antigen and telomerase reverse transcriptase in circulating tumor cells is associated with poor clinical response to the immune checkpoint inhibitor nivolumab
}

\author{
HALIN BAO $^{1 *}$, TUYA BAI ${ }^{1 *}$, KOJI TAKATA ${ }^{2 *}$, TAKEHIKO YOKOBORI ${ }^{1,3}$, TAKASHI OHNAGA $^{2}$, \\ TAKESHI HISADA ${ }^{4}$, TOSHITAKA MAENO ${ }^{4}$, PINJIE BAO ${ }^{1}$, TOMONORI YOSHIDA ${ }^{1}$, YUJI KUMAKURA ${ }^{1}$, \\ HIROAKI HONJO $^{1}$, MAKOTO SAKAI ${ }^{1}$, MAKOTO SOHDA ${ }^{1}$, MINORU FUKUCHI ${ }^{1}$, BOLAG ALTAN ${ }^{5}$, \\ TADASHI HANDA ${ }^{6}$, MUNENORI IDE ${ }^{6}$, TATSUYA MIYAZAKI ${ }^{1}$, KYOICHI OGATA $^{1}$, \\ TETSUNARI OYAMA $^{6}$, KIMIHIRO SHIMIZU $^{7}$, AKIRA MOGI $^{7}$, TAKAYUKI ASAO $^{8}$, \\ KEN SHIRABE $^{7,9,10}$, HIROYUKI KUWANO ${ }^{1,7}$ and KYOICHI KAIRA ${ }^{5}$
}

\footnotetext{
${ }^{1}$ Department of General Surgical Science, Graduate School of Medicine, Gunma University, Maebashi, Gunma 371-8511;

${ }^{2}$ Toyama Industrial Technology Center, Takaoka, Toyama 933-0981; ${ }^{3}$ Research Program for Omics-based Medical Science,

Division of Integrated Oncology Research, Gunma University Initiative for Advanced Research; Departments of

${ }^{4}$ Respiratory Medicine, ${ }^{5}$ Oncology Clinical Development and ${ }^{6}$ Diagnostic Pathology, Graduate School of Medicine, Gunma University, Maebashi, Gunma 371-8511; ${ }^{7}$ Integrative Center of General Surgery, Gunma University Hospital,

Maebashi, Gunma, 371-8510; ${ }^{8}$ Big Data Center for Integrative Analysis, Gunma University Initiative for Advance Research; ${ }^{9}$ Department of Hepatobiliary and Pancreatic Surgery, Graduate School of Medicine, Gunma University, Maebashi, Gunma 371-8511, Japan
}

Received July 10, 2017; Accepted December 13, 2017

DOI: $10.3892 / \mathrm{ol} .2017 .7671$

\begin{abstract}
The present study aimed to enrich circulating tumor cells (CTCs) from blood samples using a new size-sorting CTC chip. The present study also set out to identify a blood sensitivity marker for the immune checkpoint inhibitor nivolumab in patients with advanced, pre-treatment lung cancer. The CTC sorting efficacy of the chip was investigated and the large cell fraction of blood samples from 15 patients with pre-treatment lung cancer who were later administered nivolumab were purified. The expression levels of carcinoembryonic antigen (CEA), human Telomerase Reverse Transcriptase (hTERT), cytokeratin19 (CK19), and programmed death ligand-1 (PD-L1) were investigated to clarify the association between these CTC markers and the clinical response to nivolumab. The CTC chip effectively enriched cells from lung cancer cell line PC-9. The
\end{abstract}

Correspondence to: Dr Takehiko Yokobori, Department of General Surgical Science, Graduate School of Medicine, Gunma University, 3-39-22 Showamachi, Maebashi, Gunma 371-8511, Japan E-mail: bori45@gunma-u.ac.jp

${ }^{*}$ Contributed equally

Key words: immune checkpoint inhibitor, circulating tumor cells, CTC chip, size sorting large cell fraction had a high expression of CEA and hTERT, with the former being significantly associated with the clinical response to nivolumab. The expression of CEA and hTERT in CTCs derived from the blood of a patient with lung cancer were also validated. The evaluation of $C E A$ and possibly $h T E R T$ in CTCs collected by the CTC chip may represent a promising predictive blood marker for sensitivity to nivolumab. To the best of our knowledge this is the first report to describe the predictive CTC marker for nivolumab in pre-treatment patients.

\section{Introduction}

Immune checkpoint inhibitors have recently attracted attention as an innovative cancer therapy (1). Programmed death 1 (PD-1)/programmed death ligand-1 (PD-L1) checkpoint inhibitors have been shown to have a continuous clinical effect and low toxicity in some responder patients with several types of recurrent and metastatic diseases (2). Among these, the anti PD-1 monoclonal antibody nivolumab has led to a good clinical response in several cancer patients with lung cancer, melanoma, and renal cell carcinoma (3-6). However, many cancer patients do not gain sufficient benefits even with the anti-PD-1 antibody treatment. Some researchers have proposed that the level of PD-L1 expression and the DNA mismatch-repair status in a tumor are biomarker candidates for predicting the sensitivity to immune checkpoint blockade $(3,7)$. However, invasive tumor sampling is required to determine the protein expression and DNA status in tumor cells. Therefore, 
further research is needed globally to identify a new blood biomarker that does not require invasive sampling.

In cancer patients, circulating tumor cells (CTCs) in peripheral blood have been identified as a reliable blood tumor marker $(8,9)$. The evaluation of CTCs generally includes an enrichment step and detection processes depending on the CTC characteristics, such as tumor size, density, and cell surface antigen expression, which are conducted using a cytometric-based or polymerase chain reaction (PCR)-based method (10). Nagrath et al (11), were the first to report on a new microfluid device known as a CTC chip that was coated with epithelial cell adhesion molecule (EpCAM) antibody, which could be used to collect CTC-expressing EpCAM from whole blood samples of cancer patients. Because CTCs are known to be larger than nearly all normal blood cells $(12,13)$, the use of only the large cells in blood samples as PCR templates will enable CTCs to be detected more easily using a highly sensitive PCR-based method against the CTC markers carcinoembryonic antigen (CEA), human Telomerase Reverse Transcriptase (hTERT), cytokeratin 19 (CK19), and $P D-L 1$ (9,14-16). Therefore, in the present study, we used a modified CTC chip that was based on a continuous particle separation method (17) to enrich CTCs according to cell size.

The purpose of the present study was to utilize this new CTC chip to collect the large cell fraction from whole blood samples and to find a blood sensitivity marker for nivolumab in advanced, pre-treatment lung cancer patients. To do this, we first examined the sorting efficacy of the new CTC chip using the lung cancer cell line PC-9 and then evaluated the mRNA expression of the CTC markers CEA, hTERT, CK19, and $P D-L 1$ in the large cell fraction of clinical lung cancer patients' blood samples collected by this chip.

\section{Materials and methods}

Preparation of a polymeric CTC chip for size sorting. A polymeric CTC chip for size sorting was produced as previously described (18). The chip was set in a holder to enable liquid samples to flow from two inlets to two outlets. Cell suspension samples and mere buffer were sent from each inlet tube into the CTC chip at $0.2 \mathrm{ml} / \mathrm{min}$ using a syringe pump (Fig. 1). Two outlets were used to allow the large cell fraction including CTCs to be enriched and blood cells in the small cell fraction to be collected separately. Since the diagonally-arranged microposts cannot influence the flow of small cells, these are carried into the small cell fraction simply as a result of the buffer flow. By contrast, large cells, which include CTCs, are sorted by the microposts based on their size (Fig. 1B and C). Blood samples from advanced lung cancer patients were obtained before nivolumab treatment and collected into ethylenediaminetetraacetic acid (EDTA) blood collection tubes. A 1-ml aliquot of these blood samples was then diluted two times with phosphate-buffered saline (PBS) before size sorting using the CTC chip. Once the large cell fraction had been collected, it was used for further analysis.

Clinical samples and cell lines. This study was prospectively conducted on 15 patients at Gunma University Hospital, Japan, who had advanced lung cancer and were candidates for nivolumab treatment (Table I). The inclusion criteria for this study were as follows: pathologically proven lung cancer; recurrent lung cancer candidate for nivolumab as a result of progressive disease (PD) following chemotherapy; Eastern Cooperative Oncology Group (ECOG) performance status of 0-2, 2- $\left[{ }^{18} \mathrm{~F}\right]$-fluoro-2-deoxy-D-glucose $\left({ }^{18} \mathrm{~F}-\mathrm{FDG}\right)$ positron emission tomography/computed tomography (PET/CT) scheduled before and after the first cycle of nivolumab therapy; no evidence of concurrent cancer; no uncontrolled diabetes mellitus; no interstitial pneumonia or pulmonary fibrosis; and adequate organ function.

A pre-treatment ${ }^{18} \mathrm{~F}-\mathrm{FDG}-\mathrm{PET} / \mathrm{CT}$ study and blood sampling for CTC sorting were performed as part of the disease evaluation workup prior to the administration of nivolumab. If the tumor size was successfully suppressed by 3 months after the initiation of nivolumab, a subsequent post-treatment PET/CT was considered at around this time at the discretion of the investigator. The clinical response to nivolumab was assessed from the ${ }^{18} \mathrm{~F}-\mathrm{FDG}$ uptake and chest CT of these patients, and categorized as a partial response (PR), stable disease (SD), or PD according to the Response Evaluation Criteria in Solid Tumors (RECIST). All blood samples were prospectively collected and used in accordance with the Helsinki Declaration and the guidelines of the Gunma University Ethical Review Board for Medical Research Involving Human Subjects after obtaining written informed consent from each patient (approval no. 1404).

The human lung cancer cell line PC-9 and breast cancer cell lines MCF7 and MDA-MB-231 were used to examine the efficacy of the CTC chip for sorting cancer cells according to size. These cell lines were provided by the RIKEN BioResource Center and the American Type Culture Collection. The cells were cultured in Roswell Park Memorial Institute (RPMI) 1640 medium supplemented with 100 units/ml penicillin, 100 units/ml streptomycin, and $10 \%$ fetal bovine serum (FBS) in a humidified $5 \%-\mathrm{CO}_{2}$ incubator at $37^{\circ} \mathrm{C}$. Before cell sorting, these cells were labeled using the CellTrace ${ }^{\mathrm{TM}}$ Carboxyfluorescein Diacetate Succinimidyl Ester (CFSE) Cell Proliferation kit (Thermo Fisher Scientific, Inc., Waltham, MA, USA), according to the manufacturer's protocol. The labeled cells were then spiked into the CTC chip and separated into the small or large cell fraction (Fig. 2A), following which the sorted cancer cells in each fraction were counted microscopically.

Reverse transcription-polymerase chain reaction (RT-PCR). To discover a useful biomarker for predicting patients' sensitivity to the immune checkpoint inhibitor nivolumab, we examined the relationships between the clinical response to nivolumab and several genetic and CTC markers, including epidermal growth factor receptor $(E G F R)$ gene mutation, anaplastic lymphoma kinase $(A L K)$ fusion gene mutation, CEA levels in the serum, and the expressions of existing CTC markers in the large cell fraction including $C E A, h T E R T, C K 19$, and $P D-L 1$ in advanced lung cancer patients. RNA extraction and reverse transcription were performed using NucleoSpin RNA XS kit and PrimeScript RT reagent kit with gDNA Eraser (Takara Bio Inc., Tokyo, Japan) according to the manufacturer's protocol. The following gene-specific oligonucleotide primers were designed for PCR: The CEA (66 bp) sense primer 5'-ACCACAGTCACGACGATC AC-3' and antisense primer 5'-GGAGTTGTTGCTGGTGAT 
Table I. Clinicopathological characteristics including genetic backgrounds and circulating tumor cell marker expression in 15 patients with lung cancer.

\begin{tabular}{lllllllllll}
\hline & & \multicolumn{2}{c}{ EGFR } & ALK & CEA in & & & \\
Age & Gender & Histology & gene mutation & fusion gene & serum $(\mathrm{ng} / \mathrm{ml})$ & CEA & hTERT & CK19 & PDL1 & Response \\
\hline 74 & Female & SqCC & Unknown & Unknown & 7.9 & Low & Low & Negative & Negative & PR \\
48 & Male & AdenoCa & No & No & 1.2 & Low & Low & Negative & Negative & PR \\
64 & Male & AdenoCa & No & No & 4.3 & Low & Low & Negative & Negative & PR \\
66 & Male & AdenoCa & No & No & 8.8 & Low & Low & Negative & Negative & PR \\
82 & Male & AdenoCa & No & No & 9.3 & High & High & Negative & Negative & SD \\
73 & Male & SqCC & No & No & Unknown & High & High & Negative & Negative & SD \\
73 & Male & SqCC & Unknown & Unknown & Unknown & Low & High & Negative & Negative & SD \\
47 & Male & AdenoCa & No & No & 11342 & Low & High & Negative & Positive & SD \\
57 & Male & AdenoCa & Yes (T790M) & No & 70.6 & Low & High & Negative & Positive & SD \\
52 & Male & AdenoCa & No & No & 99.7 & High & Low & Negative & Negative & SD \\
62 & Male & AdenoCa & No & No & 3.7 & Low & Low & Positive & Negative & SD \\
78 & Male & AdenoCa & Yes & No & 1.8 & High & High & Negative & Negative & PD \\
63 & Male & AdenoCa & No & No & 41.6 & High & High & Negative & Negative & PD \\
70 & Male & AdenoCa & No & No & 4.4 & High & Low & Negative & Negative & PD \\
72 & Female & AdenoCa & No & Yes & 5.5 & High & Low & Negative & Negative & PD
\end{tabular}

EGFR, epidermal growth factor receptor; ALK, anaplastic lymphoma kinase; CEA, carcinoembryonic antigen; hTERT, human telomerase reverse transcriptase; CK19, cytokeratin 19; PDL-1, programmed death ligand-1; PR, partial response; SD, stable disease; PD, progressive disease; SqCC, squamous cell carcinoma; AdenoCa, adenocarcinoma.

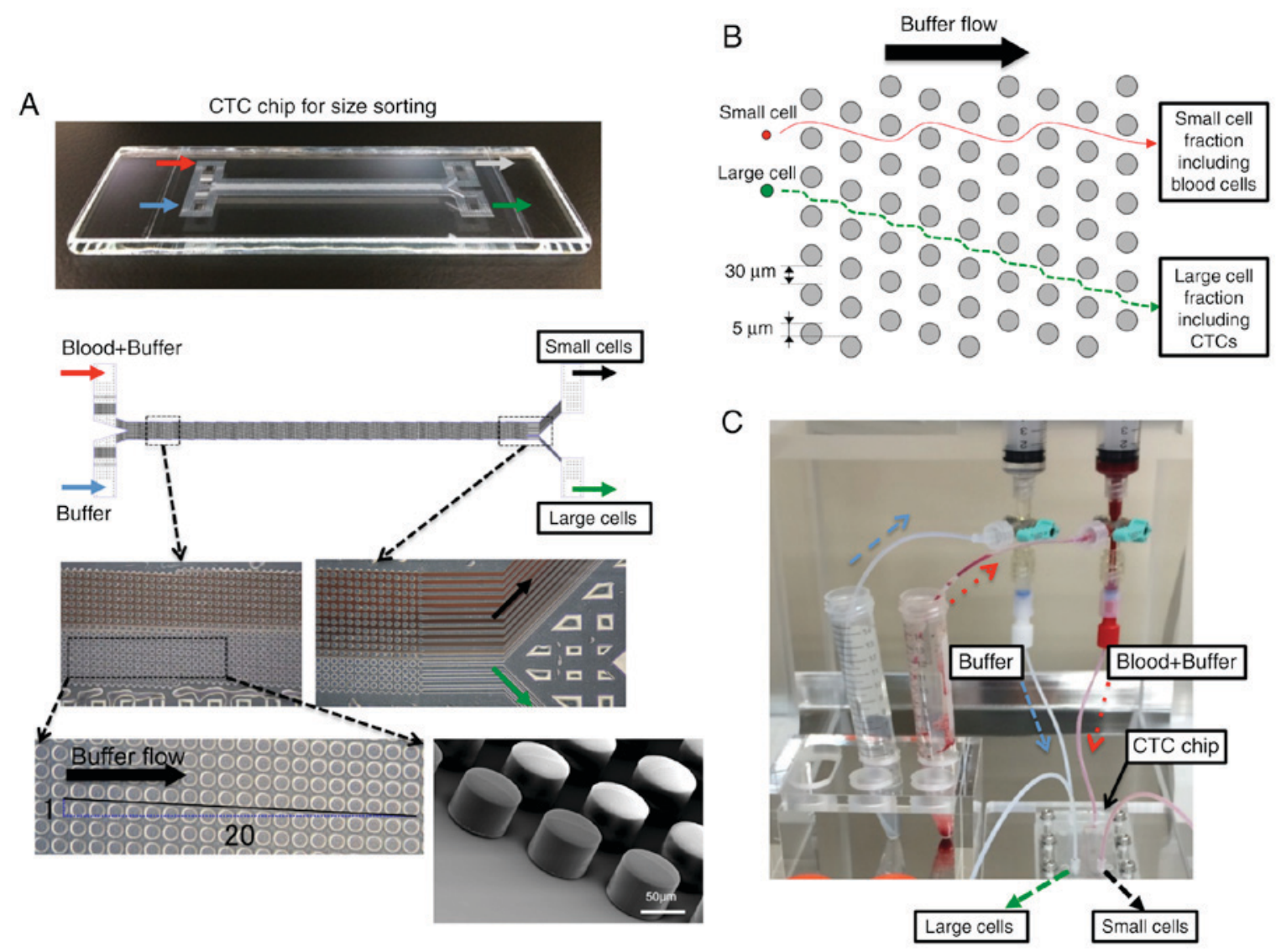

Figure 1. Images of the polymeric circulating tumor cell (CTC) chip for size sorting. (A) Whole image of the CTC chip showing the two inlets for buffer only and buffer plus blood samples, and the two outlets for the large cell fraction including CTCs and the small cell fraction including blood cells. The bottom panel shows that microposts (50 $\mu \mathrm{m}$ high, $70 \mu \mathrm{m}$ diameter) were arranged diagonally for cell sorting depending on cell size. (B) Diagram showing the sorting mechanism in the CTC chip. Small cells move from the inlet side to the outlet side as a result of the buffer flow. By contrast, large cells are moved to one side by the microposts in the CTC chip. (C) Sample flow system comprised of two inlet tubes, a syringe pump, the structured CTC chip, and two outlet tubes. 


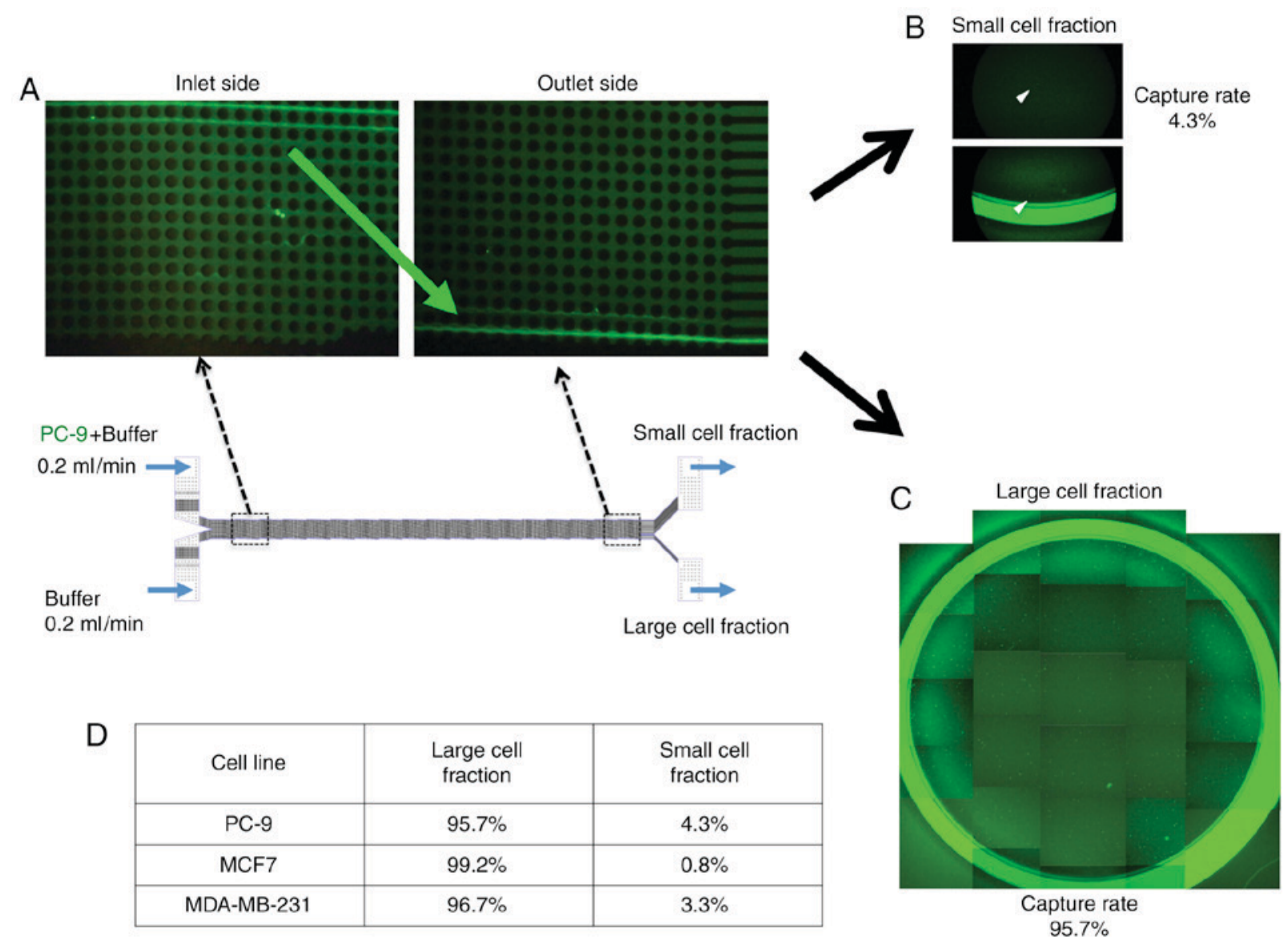

Figure 2. The circulating tumor cell (CTC) chip effectively sorted the lung cancer cell line PC-9 as the large cell fraction. (A) Diagram showing how the sorting efficacy of the CTC chip was evaluated using cancer cells labeled with carboxyfluorescein diacetate succinimidyl ester (CFSE) according to the manufacturer's protocol. (B, C) Green-labeled PC-9 cells were moved to the large fraction side. Almost all PC-9 cells were sorted into the large cell fraction according to the cell size. (D) Summary of capture ratio in PC-9, MCF7 and MDA-MB-231 cells using our CTC chip.

G-3'; the hTERT (61 bp) sense primer 5'-GCCTTCAAGAGC CACGTC-3' and antisense primer 5'-CCACGAACTGTCGCA TGT-3'; the $C K 19$ (126 bp) sense primer 5'-GCCACTACTACA CGACCATCC-3' and antisense primer 5'-CAAACTTGGTTC GGAAGTCAT-3'; the PD-L1 (124 bp) sense primer 5'-CTA CTGGCATTTGCTGAACG-3' and antisense primer 5'-TGC AGCCAGGTCTAATTGTTT-3'; and the 18S ribosomal RNA (rRNA) sense primer 5'-GATGGTAGTCGCCGTGCC-3' and antisense primer 5'-GCCTGCTGCCTTCCTTGG-3'. PCR amplification was performed in a LightCycler ${ }^{\circledR}$ system (Roche Diagnostics, Basel, Switzerland) using the LightCycler 480 SYBR Green I Master kit, as previously described (19). Each of the 40 amplification cycles comprised initial denaturation at $95^{\circ} \mathrm{C}$ for $10 \mathrm{~min}$, followed by denaturation at $95^{\circ} \mathrm{C}$ for $10 \mathrm{sec}$, annealing at $62^{\circ} \mathrm{C}$ for $10 \mathrm{sec}$, and elongation at $67^{\circ} \mathrm{C}$ for $10 \mathrm{sec}$. The relative expression levels of these genes were obtained by normalizing the amount of mitochondrial RNA (mRNA) to that of 18S rRNA as an endogenous control in each sample.

Fluorescent immunohistochemistry. Sorted cells were seeded on glass coverslips and incubated for $12 \mathrm{~h}$ at $37^{\circ} \mathrm{C}$. After washing with PBS to exclude non-attached circulating cells such as lymphocytes, the cells were fixed with $100 \%$ methanol at $-20^{\circ} \mathrm{C}$ for $15 \mathrm{~min}$, and then incubated with mouse CEA antibody (1:100) (Kyowa Medex Co., Ltd., Tokyo, Japan) and rabbit
hTERT antibody (Abcam, Cambridge, CA, USA) for $1 \mathrm{~h}$ at room temperature. To detect antibodies against CEA and hTERT, fluorophore-labeled antibodies with anti-mouse fluorescein isothiocyanate (FITC) and anti-rabbit Cy3 specificities (Thermo Fisher Scientific, Inc.) were used for $1 \mathrm{~h}$ at room temperature at a dilution of 1:2,000. All sections were then counterstained with 4',6-diamidino-2-phenylindole (DAPI) and examined under an All-in-One BZ-X710 Fluorescence Microscope (Keyence Corporation, Osaka, Japan). Negative control sections were stained as described above but without the primary antibodies.

Statistical analysis. The relationship between the number of patients with positive marker expression in the large cell fraction and the clinical response to nivolumab was analyzed using Pearson's chi-square test. All statistical analyses were performed using the JMP software package (SAS Institute, Inc., Cary, NC, USA).

\section{Results}

The new polymeric microfluid CTC chip effectively collected lung cancer cell line PC-9 into the large cell fraction. To examine the capture efficacy of lung cancer cells using the size-sorting CTC chip device, we spiked the CTC chip with CFSE-labeled PC-9 cells and counted how many entered the small and large cell fractions (Fig. 2). We found that nearly 

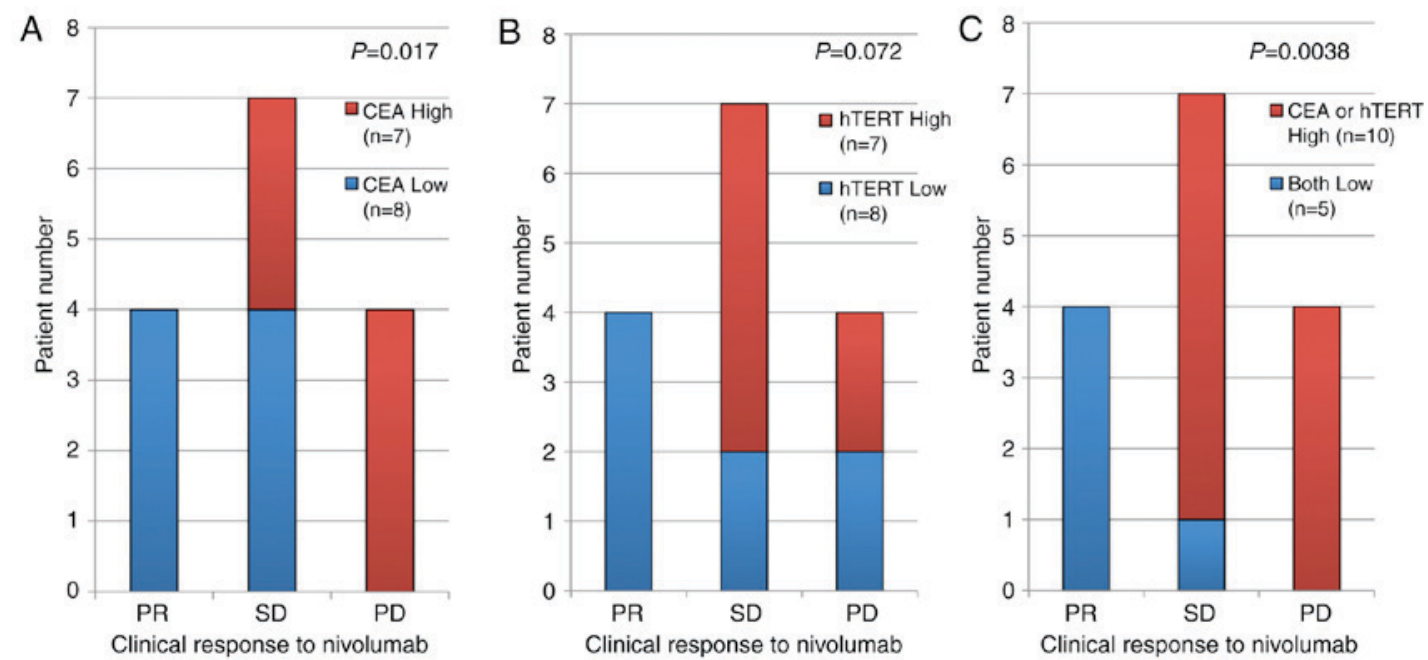

Figure 3. Circulating tumor cell (CTC) marker expression and the clinical response to nivolumab in advanced lung cancer patients. (A) High mRNA expression level of carcinoembryonic antigen $(C E A)$ in the large cell fraction was significantly associated with a poor clinical response to nivolumab $(\mathrm{P}=0.017)$. High $C E A$ expression group, $n=7$; low $C E A$ expression group, $n=8$. (B) A high mRNA expression level of human Telomerase Reverse Transcriptase ( $h T E R T$ ) in the large cell fraction tended to be associated with a poor clinical response to nivolumab $(\mathrm{P}=0.072)$. High $h T E R T$ expression group, $n=7$; low hTERT expression group, $n=8$. (C) Low mRNA expression of both the markers was strongly associated with PR clinical response ( $\mathrm{P}=0.0038)$. High expression group, $n=10$; both low expression group, $n=5$. Expression levels were normalized to $18 S$ rRNA expression in the large cell fraction.
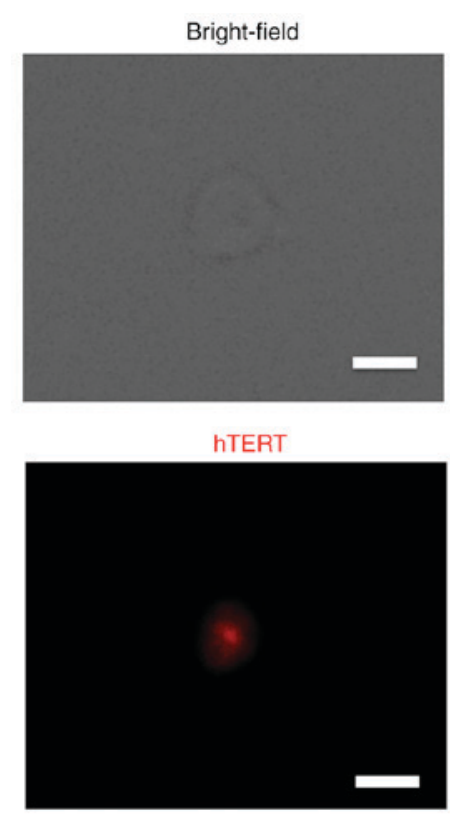

Nucleus

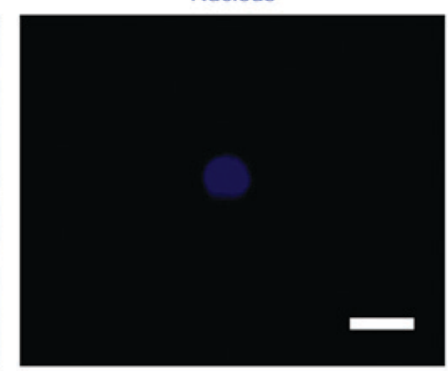

Merged

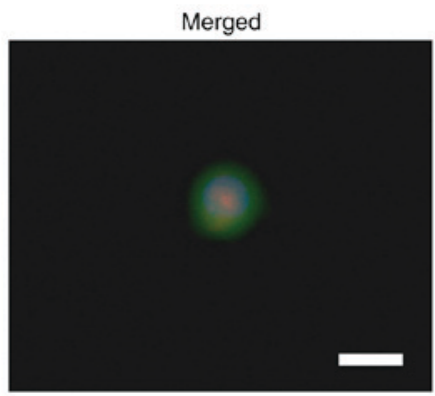

CEA

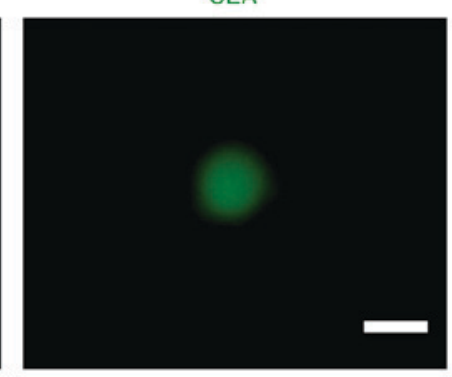




\section{Discussion}

In the present study, we designed a new CTC chip that could effectively sort PC-9 cells from a cell suspension in vitro depending on their size. Moreover, we demonstrated that this CTC chip was able to collect the large cells including CTCs from whole blood and that a high expression level of $C E A$ in this fraction was significantly correlated with a poor clinical response in clinical lung cancer patients treated with the anti-PD-1 antibody nivolumab. By contrast, serum CEA levels and the expression of other markers in the large cell fraction, such as the representative epithelial marker $C K 19$ and $P D-L 1$, were not associated with the clinical response to nivolumab.

In general, it is important for cancer cells to avoid immune surveillance not only at the primary site but also in the bloodstream to allow them to survive. However, cancers also have several other hallmarks that help with their survival, including the ability to sustain proliferative signaling; evade growth suppressors; enable replicative immortality and tumor-promoting inflammation; activate invasion and metastasis; induce angiogenesis, genome instability, and mutation; resist cell death; and deregulate cellular energetics (20). It has previously been reported that $C E A$ and $h T E R T$ may help in the proliferation, inflammation, angiogenesis, metastasis, resistance to apoptosis, DNA damage repair, and replicative immortality of cancers, which are expected to be important for their survival (20-22). Consequently, it has been suggested that if cancers depend on avoiding immune destruction for their survival, the immune checkpoint inhibitor nivolumab would be an effective treatment, whereas if they are not depending on this, nivolumab may not induce an anti-cancer effect against the cancer cells with other hallmark characteristics. Thus, the use of the method outlined here for detecting CEA and hTERT in CTCs in combination with nivolumab treatment may prove useful for evaluating whether the cancers in advanced lung cancer patients are depending on avoiding immune destruction for their survival.

Several methods for enriching and detecting CTCs in blood samples from clinical cancer patients have previously been reported $(8,9,23)$. Here, we used a CTC chip to enrich CTCs, which is a morphology-based isolation technique that related to the isolation by size of epithelial tumor cells (ISET) method (24), Ficoll isolation for collecting CTC and mononuclear cells, and RosetteSep ${ }^{\mathrm{TM}}$ (25). This size-sorting CTC chip was able to enrich lung cancer cells in vitro and in clinical samples. We chose to use a PCR-based method with high sensitivity to detect CTCs from the large cell fraction because CTCs are known to be rare in the blood (one CTC per $10^{6}-10^{7}$ mononuclear cells; [10]). This combination of a size-sorting CTC chip and high-sensitivity PCR-based CTC detection technology may be more suitable for evaluating sensitivity to the immune checkpoint inhibitor nivolumab than the mere detection of CTCs in blood samples.

Commercially available CTC chip using epithelial antibody-based detection methods could capture the cancer cell lines expressing epithelial markers such as MCF7. However, epithelial mesenchymal transition (EMT) induced cancer cells including MDA-MB-231 with highly aggressive phenotypes were not captured by these types of CTC chips $(26,27)$. In contrast, our CTC chip is based on cell size, not epithelial markers. We could demonstrate the high capture ratio of EMT-induced cancer cell line MDA-MB-231 using our CTC chip. From these data, it was suggested that our CTC chip may be more effective in sorting the EMT-induced aggressive CTC than epithelial marker dependent CTC detection.

There is a need to develop a sensitivity marker for immune checkpoint inhibitors including nivolumab in the clinic because these agents are very expensive and have characteristic side effects including an autoimmune response against several organs. It has previously been reported that the overexpression of PD-L1 and somatic mutations that encode immunogenic neoantigens are significantly related to a better response to PD-1/PD-L1 blockade therapy in several cancers (3). However, we are in urgent need of a useful predictive biomarker that uses blood because invasive tumor sampling is currently required to detect PD-L1 expression and mutations for neoantigens in tumor cells. The method outlined in the present study could predict nivolumab sensitivity before treatment using only $1 \mathrm{ml}$ of blood from a cancer patient, making it very promising. However, our data have some limitations: We only validated the immunostaining of CTC markers, CEA, hTERT in a few clinical lung cancer patients in this study, and the limited number of patients that were used in this study; therefore, more patients need to be involved in future studies to elucidate the clinical potential of these methods.

In conclusion, we successfully developed a new polymeric CTC chip that can sort CTCs from blood samples based on their size. The CTCs in the large cell fraction expressed the existing CTC markers CEA and $h T E R T$, the high expression of which was associated with a poor clinical response to the immune checkpoint inhibitor nivolumab in advanced lung cancer patients. Evaluation of CEA and hTERT in CTCs may be a predictive blood marker candidate for patient sensitivity to nivolumab.

\section{Acknowledgements}

The present study was supported by JSS Young Researcher Award from Japan Surgical Society, Gunma University Clinical Biobank, and grants-in-Aid for Scientific Research from the Japan Society for the Promotion of Science (JSPS) (grant nos. JP 26461969, JP15K10129, JP15K10085, and JP26350557).

\section{References}

1. Sharma P and Allison JP: The future of immune checkpoint therapy. Science 348: 56-61, 2015.

2. Ma W, Gilligan BM, Yuan J and Li T: Current status and perspectives in translational biomarker research for PD-1/PD-L1 immune checkpoint blockade therapy. J Hematol Oncol 9: 47, 2016.

3. Meng X, Huang Z, Teng F, Xing L and Yu J: Predictive biomarkers in PD-1/PD-L1 checkpoint blockade immunotherapy. Cancer Treat Rev 41: 868-876, 2015.

4. Borghaei H, Paz-Ares L, Horn L, Spigel DR, Steins M, Ready NE, Chow LQ, Vokes EE, Felip E, Holgado E, et al: Nivolumab versus docetaxel in advanced nonsquamous non-small-cell lung cancer. N Engl J Med 373: 1627-1639, 2015.

5. Robert C, Long GV, Brady B, Dutriaux C, Maio M, Mortier L, Hassel JC, Rutkowski P, McNeil C, Kalinka-Warzocha E, et al: Nivolumab in previously untreated melanoma without BRAF mutation. N Engl J Med 372: 320-330, 2015.

6. Motzer RJ, Escudier B, McDermott DF, George S, Hammers HJ, Srinivas S, Tykodi SS, Sosman JA, Procopio G, Plimack ER, et al: Nivolumab versus everolimus in advanced renal-cell carcinoma. N Engl J Med 373: 1803-1813, 2015. 
7. Le DT, Uram JN, Wang H, Bartlett BR, Kemberling $H$ Eyring AD, Skora AD, Luber BS, Azad NS, Laheru D, et al: PD-1 Blockade in tumors with mismatch-repair deficiency. N Engl J Med 372: 2509-2520, 2015

8. Pantel K and Alix-Panabières C: Circulating tumour cells in cancer patients: Challenges and perspectives. Trends Mol Med 16: 398-406, 2010.

9. Alix-Panabières $\mathrm{C}$ and Pantel $\mathrm{K}$ : Challenges in circulating tumour cell research. Nat Rev Cancer 14: 623-631, 2014.

10. Sun YF, Yang XR, Zhou J, Qiu SJ, Fan J and Xu Y: Circulating tumor cells: Advances in detection methods, biological issues, and clinical relevance. J Cancer Res Clin Oncol 137: 1151-1173, 2011.

11. Nagrath S, Sequist LV, Maheswaran S,Bell DW, Irimia D, Ulkus L, Smith MR, Kwak EL, Digumarthy S, Muzikansky A, et al: Isolation of rare circulating tumour cells in cancer patients by microchip technology. Nature 450: 1235-1239, 2007.

12. Dong Y, Skelley AM, Merdek KD, Sprott KM, Jiang C, Pierceall WE, Lin J, Stocum M, Carney WP and Smirnov DA Microfluidics and circulating tumor cells. J Mol Diagn 15: 149-157, 2013.

13. Seal SH: A sieve for the isolation of cancer cells and other large cells from the blood. Cancer 17: 637-642, 1964.

14. Yu Y, Xu G, Cao J, Jin S, Man Y and Shang L: Combination of four gene markers to detect circulating tumor cells in the peripheral blood of patients with advanced lung adenocarcinoma using real-time PCR. Oncol Lett 5: 1400-1406, 2013.

15. Tanaka F, Yoneda K and Hasegawa S: Circulating tumor cells (CTCs) in lung cancer: Current status and future perspectives. Lung Cancer (Auckl) 1: 77-84, 2010.

16. Mazel M, Jacot W, Pantel K, Bartkowiak K, Topart D, Cayrefourcq L, Rossille D, Maudelonde T, Fest T and Alix-Panabières C: Frequent expression of PD-L1 on circulating breast cancer cells. Mol Oncol 9: 1773-1782, 2015.

17. Huang LR, Cox EC, Austin RH and Sturm JC: Continuous particle separation through deterministic lateral displacement. Science 304: 987-990, 2004

18. Ohnaga T, Shimada Y, Moriyama M, Kishi H, Obata T, Takata K, Okumura T, Nagata T, Muraguchi A and Tsukada K: Polymeric microfluidic devices exhibiting sufficient capture of cancer cell line for isolation of circulating tumor cells. Biomed Microdevices 15: 611-616, 2013.
19. Yokobori $\mathrm{T}$, Iinuma $\mathrm{H}$, Shimamura $\mathrm{T}$, Imoto $\mathrm{S}$, Sugimachi $\mathrm{K}$, Ishii H, Iwatsuki M, Ota D, Ohkuma M, Iwaya T, et al: Plastin3 is a novel marker for circulating tumor cells undergoing the epithelial-mesenchymal transition and is associated with colorectal cancer prognosis. Cancer Res 73: 2059-2069, 2013.

20. Hanahan D and Weinberg RA: Hallmarks of cancer: The next generation. Cell 144: 646-674, 2011

21. Beauchemin $\mathrm{N}$ and Arabzadeh A: Carcinoembryonic antigen-related cell adhesion molecules (CEACAMs) in cancer progression and metastasis. Cancer Metastasis Rev 32: 643-671, 2013.

22. Cong Y and Shay JW: Actions of human telomerase beyond telomeres. Cell Res 18: 725-732, 2008.

23. Alix-Panabières $\mathrm{C}$ and Pantel $\mathrm{K}$ : Technologies for detection of circulating tumor cells: Facts and vision. Lab Chip 14: 57-62, 2014.

24. Vona G, Sabile A, Louha M, Sitruk V, Romana S, Schütze K, Capron F, Franco D, Pazzagli M, Vekemans M, et al: Isolation by size of epithelial tumor cells: A new method for the immunomorphological and molecular characterization of circulating tumor cells. Am J Pathol 156: 57-63, 2000.

25. Busch R, Cesar D, Higuera-Alhino D, Gee T, Hellerstein MK and McCune JM: Isolation of peripheral blood CD4(+) T cells using RosetteSep and MACS for studies of DNA turnover by deuterium labeling. J Immunol Methods 286: 97-109, 2004.

26. Polyak K and Weinberg RA: Transitions between epithelial and mesenchymal states: Acquisition of malignant and stem cell traits. Nat Rev Cancer 9: 265-273, 2009.

27. Ohnaga T, Shimada Y, Takata K, Obata T, Okumura T, Nagata T, Kishi H, Muraguchi A and Tsukada K: Capture of esophageal and breast cancer cells with polymeric microfluidic devices for CTC isolation. Mol Clin Oncol 4: 599-602, 2016.

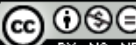

This work is licensed under a Creative Commons Attribution-NonCommercial-NoDerivatives 4.0 International (CC BY-NC-ND 4.0) License. 